\title{
A Study of Travel Time for Different Open Channels
}

\author{
Vikram Kumar ${ }^{1}$
}

Received: 2 November 2017/ Accepted: 21 February 2019/Published online: 21 March 2020

(C) The Institution of Engineers (India) 2020

\begin{abstract}
An increase in developmental activities such as afforestation, paved surfaces and construction of buildings and other structures leads to an increase in surface runoff and peak discharge from the watershed. These all cause a decrease in detention storage and surface depression and thus diminish the concentration time that flow will take and distributes flow to the adjoining stream quickly rather than that would have taken before development or urbanization. Despite the importance of time of concentration, planners and engineers are often puzzled by different profiles of the channels and their equation available in the literature without knowing the accuracy of each formula. In this paper, kinematic wave theory integrated with the Manning's equation has been applied for the comparative assessment of the performance of the various cross-sectional channels. The result of different channel profiles toward travel time of flow has been matched for nine channel profiles. Of the nine channel profiles, it was found that the deep rectangular cross-sectional channel possesses the highest time of travel. Therefore, the use of deep rectangular channel yields lesser watershed runoff. The parabolic channel with more depth yields the lesser time of travel; therefore, the use of parabolic channel profile yields larger watershed runoff.
\end{abstract}

Keywords Watershed Time of concentration . Manning's equation $\cdot$ Kinetic wave

Vikram Kumar

25.vikram@gmail.com

$1 \quad$ Hydraulics and Water Resources Engineering, Indian Institute of Technology Banaras Hindu University, Varanasi, India

\section{Introduction}

Water is one of the most vital elements for human survival as well as it is needed for agricultural, municipal, industrial and power sectors. To fulfill the demand for water from various end users, it needs to be conveyed from one location to another location. Leakage and losses through the evaporation are the utmost serious forms of water loss in an irrigation canal network. This necessity has impelled the creativity of human to dig a channel, for transporting water as according to their place of wishes and requirements. A channel includes irrigation channels, roadside channels and drainage ditches that are either man-made with regular geometric cross sections or unlined or lined with artificial or natural material to protect against erosion. These channels and small section of parabolic cannels can be built by earthmovers and other types of earth-moving equipment [1]. The most generally utilized channel areas are rectangular, circular, triangular and trapezoidal. In a hilly watershed which involves a system of overland planes and open channels, the travel time of flow in channels upsets the surface flow attributes of the watershed. Travel time is characterized as the "normal time required for water to go from the highest point of the hillslope by means of the subsurface hillslope to the watershed outlet". In channels having extended travel time and detention storage, the watershed disturbed would have an extended time of concentration. These types of the watershed have small rainfall intensity duration frequency curves; therefore, the runoff generated from watershed will be lesser. Conversely, in channels having less travel time and lesser detention storage, the runoff generated from watershed will be enormous. Thus, the profile of the channels must have a consequence on the travel time and the detention storage of basin as suggested by Wong [2]. Henceforth, the channel 
profile can be utilized as a way to deal with the runoff from a watershed. This is, be that as it may, not honed which might be because of no distributed outcome on the impact of channel profile on the season of travel. This absence of result might be because of the troubles in playing out an exploratory or a numerical review. Then again, with an insignificant cost and in a moderately brief time, the impact of channel profile on the season of travel can be contemplated hypothetically.

Time of concentration (Tc) of the stream is an essential parameter in numerous hydrologic configuration forms. Time of concentration study started with Henderson and Wooding [3] equation for a solitary plane. However, this theory could not be effortlessly connected in practice because of the fact that it included parameters which were not identified with the physical qualities of an overland. Tc is an essential parameter in seepage framework plan of a watershed. In the method for the kinematic wave hypothesis $(\mathrm{KWH})$, it is conceivable to get a scientific travel time equation for certain exaggerated channel conditions. In case of fluid mass flows through the channels, kinematic wave hypothesis plays a key role to understand the elementary features of the associated wave phenomena. In these hypotheses, mass and momentum equations are combined to yield a kinematic wave (KW) equation. Depending upon the kinematic wave, it is governed by a simple partial differential equation (PDE) with a single unknown function (e.g., the flow or wave height, h) in terms of the two independent variables, namely the time and the space with some coefficients which contains information about the flow characteristics. Wong [4] built up a condition, which can be connected to different planes having distinctive lengths, slopes, roughnesses, stream regimes, soil sorts and infiltration degrees with various net precipitation Intensities. Further, in light of the KWH, a summed up travel time for an alternate profiled channels was created that is pertinent to the general channels subject to a uniform sidelong inflow and a steady upstream inflow.

Chow [5] gave different properties of ideal segments and communicated the relations between the segment factors of the most powerfully effective segments for various channel profiles. His review reflected the conveyance of a given flow rate with the least flow area. The limitation of this model was only the condition of uniform discharge. The after effects of his review are still being used for comparing different channel types. The relations obtained for the ideal channel section variables were adjusted by considering distinctive parameters for overland streams. Kinematic wave conditions can be connected to most overland stream circumstances, and it determines its quality by having the possibility of getting physically based procedures without the requirement for any experimentation and they combined the kinematic wave (kw) Tc equation with Manning's condition and inferred the Tc equation [2 and 5]. A correlation of conditions is proposed by Woolhiser, and Liggett and USDA [6 and 7] demonstrated that the rearrangements should be possible by changing precipitation intensity in technique USDA [7]. USDA [7] proposed an adjusted kw Tc equation, which was additionally identified with a steady precipitation. Chen and Wong [8] inferred the condition by coupling the kw Tc with the Darcy-Weisbach equation. Swamee with another co-author [9] proposed unequivocal conditions for channel section factors considering rectangular, trapezoidal, circular and triangular waterway geometries. The authors have considered the minimization of waterway cost as the target of the work.

Wong [10] evaluated the significance of overland Tc on the design flow rate and analyzed the execution nine procedures published somewhere around 1946 and 1993, which are planned for overland flow just that is subjected to uniform precipitation. The evaluation contrasts the assessments from the methods and experimental values that are determined under similar conditions for two surfaces, in particular, cement and grass. The evaluation demonstrates that equation that doesn't represent the rainfall intensity is substantial for a restricted scope of rainfall intensity. The equation that records for the rainfall intensity, for the most part, shows better concurrence with the experimental information. At last, the appraisal gives two rankings of the equations for the two different surfaces in agreement to their precision when contrasted with the experimental information. Chahar [11] exhibited ideal outline conditions for a parabolic channel/trench. The framework conditions for the lowest earthwork cost and least lined cost segment were in the unequivocal frame and result in ideal measurements of a waterway in single stride calculations. The condition was obtained in the wake of applying the Fibonacci look strategy on a nonlinear unconstrained improvement issue. Easa [12] demonstrated channel cross area with illustrative sides and even base to more practical (give lesser development cost per unit length) than the trapezoidal cross segment. Munier [13] processed precisely the reaction time of an open channel which is of extraordinary significance for administration operations on waterway systems, for example, encouraging forward control issues. Chow [14] enumerates the values of " $n$ " for different channels.

The above literature reveals that a significant amount of work was carried out to determine the optimal dimensions of a channel for given site conditions. Several optimization techniques were also used to either minimize the construction cost of a channel or to enhance their conveyance capability. In fact, the conveyance capacity of a channel affects the time of concentration and detention storage characteristics. Therefore, the profiles of channel or 
tributaries of a given watershed area play a vital role in deciding watershed response to the overland flow, flood management practices and irrigation pattern of the proposed reach. Kinematic wave theory was employed to understand the conveyance characteristics of the overland flow, wherein a modified form of Manning's equation is used. In the present study, nine standard different channel profiles of open channel [deep rectangular (D); wide rectangular $(\mathrm{W})$; square $(\mathrm{S})$; triangular $(\mathrm{T})$; parabolic $(\mathrm{P})$; vertical curb $(\mathrm{V})$; circular $(\mathrm{C})$; trapezoidal with equal side slopes $(\mathrm{E})$; and trapezoidal with one side vertical $(\mathrm{O})]$ for given discharge, uniform lateral discharge and an endless upstream discharge are equated in terms of travel time.

\section{Methodology}

The construction cost of different channels in any of the hydro/irrigation work is a main cost item, and maximum low cost is accomplished through the economical channel design by considering suitable section shape and dimension. In light of the kwh, Wong [15] demonstrated that, for discharge in a channel with an inconsequential backwater impact, the celerity $(c)$ of the wave going downward to the channel is assumed to be represented by

$c=\frac{\mathrm{d} x}{\mathrm{~d} t}=\alpha^{\frac{1}{\beta}} \times \beta \times Q^{1-\left(1-\frac{1}{\beta}\right)}$

where $t=$ duration, $x=$ lateral distance of channel toward flow direction and $\alpha$ and $\beta$ are factors associated to flow rate $Q$ and flow area $A$ with relation.

$Q=\alpha A^{\beta}$

The validity of Eq. (1) is true only in case of $\alpha$ and $\beta$ are constants.

Considering a waterway or channel with a steady upstream discharge $Q_{u}$ and a lateral discharge $(q)$ that is consistently appropriated along the channel, then flow rate in the channel $(Q)$ follows Eq. (3)

$Q=Q_{u}+q x$

On substituting Eq. (3) in Eq. (4) and integrating from 0 to $t_{t}$ for time $(t)$ and 0 to $L_{c}$ for distance $(x)$, the following equation is obtained

$t_{t}=\frac{1}{\alpha^{\frac{1}{\beta}}} \times\left[\frac{\left(Q+q \times L_{c}\right)^{\frac{1}{\beta}}-\left(Q_{u}\right)^{\frac{1}{\beta}}}{q}\right]$

If the upstream flow is zero, then $Q_{u}=0$, and thus,

$t_{t}=\left(L \times q^{\frac{(1-\beta)}{\alpha}}\right)^{\frac{1}{\beta}}$

From the law of continuity, the downstream discharge of a channel segment during equilibrium $\left(Q_{d}\right)$ is related to constant upstream discharge $\left(Q_{u}\right)$ and uniform lateral discharge $(q)$; therefore, Eqs. (3 and 4 ) take the following form:

$Q_{d}=Q_{u}+q L_{c}$

$t_{t}=\frac{L c}{\alpha^{\frac{1}{\beta}}} \times\left[\frac{(Q d)^{\frac{1}{\beta}}-\left(Q_{u}\right)^{\frac{1}{\beta}}}{Q d-Q u}\right]$

Equation (7) can be written as

$t_{t}=\left[\frac{L}{\alpha \times q^{\beta-1}}\right]^{\frac{1}{\beta}} \times\left[(\lambda+1)^{\frac{1}{\beta}}-(\lambda)^{\frac{1}{\beta}}\right]$

where $\lambda$ is discharge ratio that relates upstream discharge to lateral discharge as follows:

$\lambda=\frac{Q_{u}}{q \times L}$

So as to think about the travel time for the nine different channel profiles (D, W, S, T, P, V, C, E, O) on a combined basis, S-type channel profile has been selected as a reference, because of the fewer parameters involved with it. While comparing, the different channels $(\mathrm{D}, \mathrm{W}, \mathrm{S}, \mathrm{T}, \mathrm{P}$, $\mathrm{V}, \mathrm{C}, \mathrm{E}, \mathrm{O}$ ), assume same lateral discharge and the upstream discharge together with other channel characteristics excluding the profile of channel and size. The ratio of the travel time equations for the $(\mathrm{D}, \mathrm{W}, \mathrm{S}, \mathrm{T}, \mathrm{P}$, $\mathrm{V}, \mathrm{C}, \mathrm{E}, \mathrm{O})$ channel profiles by the travel time of the square channel is summarized in Table 1 , and their notation along with figure is described in "Appendix I".

\section{Result and Discussion}

The results drawn from the present work are presented in Figs. 1, 2 and 3, which show the comparison and variation of time of travel ratio for different cross section geometries of channels with flow depth and slope. Figure 1a, b represents the variation of travel time ratio with ' $\mu$ ' for D- and W-type channel, which shows as the flow depth increases, the travel time ratio increases for D-type channel while it decreases for $\mathrm{W}$-type channel. Figure $1 \mathrm{c}, \mathrm{d}$ represents the variation of travel time ratio with ' $\mathrm{z}$ ' for $\mathrm{T}$ and $\mathrm{V}$ types of channel, which shows that as the channel side slope decreases the time travel ratio first decreases to a certain value and then increases with steep side slope to mild side slope, while Fig. 1e shows that time travel ratio for the parabolic channel with and without upstream inflow continuously decreasing with an increase in depth of flow. It means that it produces large watershed runoff. Figure 1f, $g$ represents the variation of time of travel ratio with ' $\mathrm{z}$ ' for T-type channel. E type of channel having travel time ratio decreases continuously with an increase in side slope, while this ratio goes decreasing up to certain minimum 
Table 1 Ratio of the travel time for different channels with respect to square channel

\begin{tabular}{|c|c|c|c|}
\hline \multirow[t]{2}{*}{ Channel } & \multicolumn{2}{|l|}{ Value of } & \multirow[t]{2}{*}{ Ratio of travel time of square } \\
\hline & $\alpha$ & $\beta$ & \\
\hline Square & $\frac{\sqrt{s}}{n} \times\left(\frac{1}{3}\right)^{\frac{2}{3}}$ & $\frac{4}{3}$ & 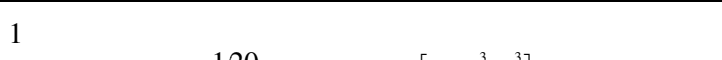 \\
\hline Wide rectangular & $\frac{\sqrt{s}}{n} \times\left(\frac{1}{W}\right)^{\frac{2}{3}}$ & $\frac{5}{3}$ & $0.577 \times\left[\frac{(1+2 \mu)^{2}}{\mu^{5}}\right]^{1 / 20} \times(\lambda+1)^{\frac{3}{20}} \times \frac{\left[(\lambda+1)^{\frac{3}{5}}-\lambda^{\frac{3}{3}}\right]}{\left[(\lambda+1)^{\frac{3}{4}}-\lambda^{\frac{3}{4}}\right]}$ \\
\hline Deep rectangular & $\frac{\sqrt{s}}{n} \times\left(\frac{W}{2}\right)^{\frac{2}{3}}$ & 1 & $0.917 \times\left(\frac{1}{\lambda+1}\right)^{\frac{1}{4}} \times\left[\frac{\mu^{5}}{(1+2 \mu)^{2}}\right]^{\frac{1}{12}} \times \frac{1}{\left[(\lambda+1)^{\frac{3}{4}}-\lambda^{\frac{3}{4}}\right]}$ \\
\hline Triangular & $\frac{\sqrt{s}}{n} \times\left[\frac{z}{4\left(1+z^{2}\right)}\right]^{\frac{1}{3}}$ & $\frac{4}{3}$ & $0.81652 \times\left[\frac{\left(1+z^{2}\right)}{z}\right]^{\frac{1}{4}}$ \\
\hline Vertical curb & $\frac{\sqrt{s}}{n} \times\left[\frac{z}{2\left(1+\sqrt{1+z^{2}}\right)^{2}}\right]^{\frac{1}{3}}$ & $\frac{4}{3}$ & $0.685 \times\left[\frac{\left(1+z^{2}\right)}{z}\right]^{\frac{1}{4}}$ \\
\hline Parabolic & $\frac{0.493 \sqrt{s}}{n} \times\left(\frac{1}{W}\right)^{\frac{2}{9}}$ & $\frac{13}{9}$ & $0.884 \times\left\{\frac{[\sqrt{\mu(1+\mu})+\ln (\sqrt{\mu}+\sqrt{1+\mu}]^{2}}{\mu^{\frac{15}{2}}}\right\}^{52} \times(1+\lambda)^{\frac{3}{52}} \times \frac{\left[(\lambda+1)^{\frac{9}{13}}-\lambda^{\frac{9}{13}}\right]}{\left[(\lambda+1)^{\frac{3}{4}}-\lambda^{\frac{3}{4}}\right]}$ \\
\hline Circular & $\frac{0.501 \sqrt{s}}{n} \times\left(W^{\prime \frac{1}{6}}\right)$ & $\frac{5}{4}$ & $0.946 \times\left(\frac{1}{\lambda+1}\right)^{\frac{1}{20}} \times \frac{\left[(\lambda+1)^{\frac{4}{5}}-\lambda^{\frac{4}{5}}\right]}{\left[(\lambda+1)^{\frac{3}{4}}-\lambda^{\frac{3}{4}}\right]}$ \\
\hline Trapezoidal with equal side slopes & $\frac{\sqrt{s}}{n} \times\left[\frac{z \psi^{\frac{1}{2}}}{z+\sqrt{1+z^{2}}\left(\sqrt{1+4 z \Psi^{\prime}}-1\right)}\right]^{\frac{2}{3}}$ & $\frac{4}{3}$ & $0.577 \times\left(\frac{z+\sqrt{1+z^{2}}(\sqrt{1+4 z \Psi}-1)}{z \Psi^{\frac{1}{2}}}\right)^{\frac{1}{2}}$ \\
\hline Trapezoidal with one side vertical & $\frac{\sqrt{s}}{n} \times\left[\frac{z \psi^{\frac{1}{2}}}{z+\left(1+\sqrt{1+z^{2}}\right)(\sqrt{1+2 z \Psi}-1)}\right]$ & $\frac{4}{3}$ & $0.577 \times\left(\frac{z+\left(1+\sqrt{1+z^{2}}\right)(\sqrt{1+2 z \Psi}-1)}{z \psi^{\frac{1}{2}}}\right)^{\frac{1}{2}}$ \\
\hline
\end{tabular}

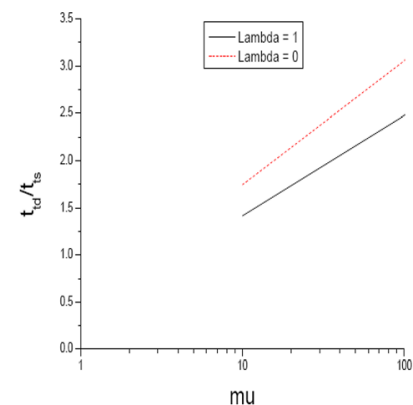

(a)

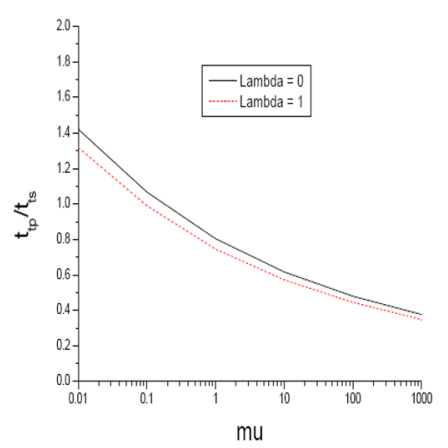

(e)

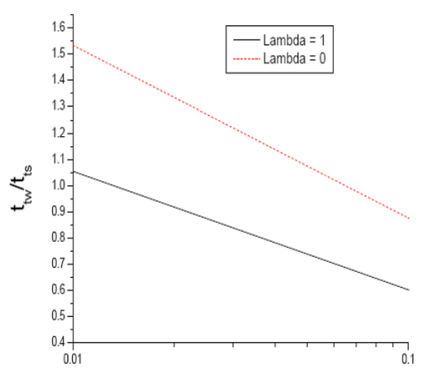

(b)

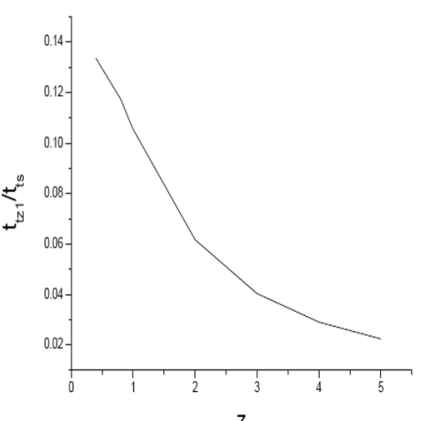

(f)

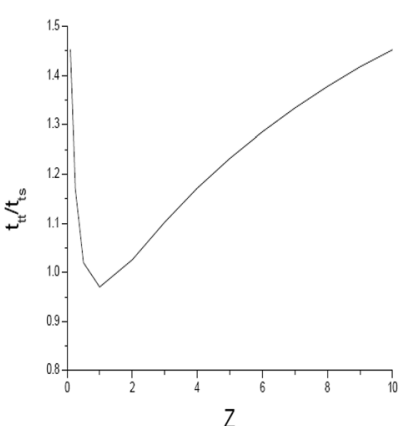

(c)

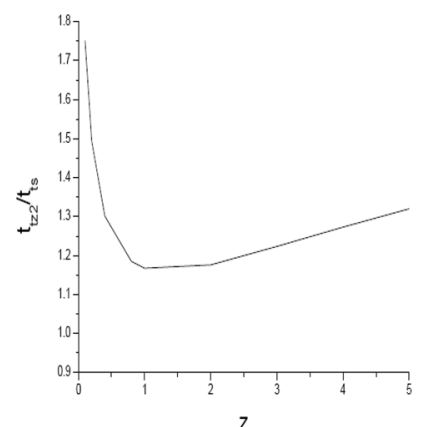

(g)

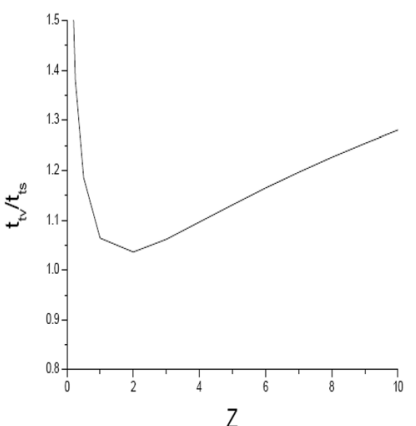

(d)

Fig. 1 a Variation of D channel, b W channel, $\mathbf{c}$ T channel, d V channel, e P channel, $\mathbf{f}$ E channel, $\mathbf{g} \mathrm{O}$ channel with respect to travel time 


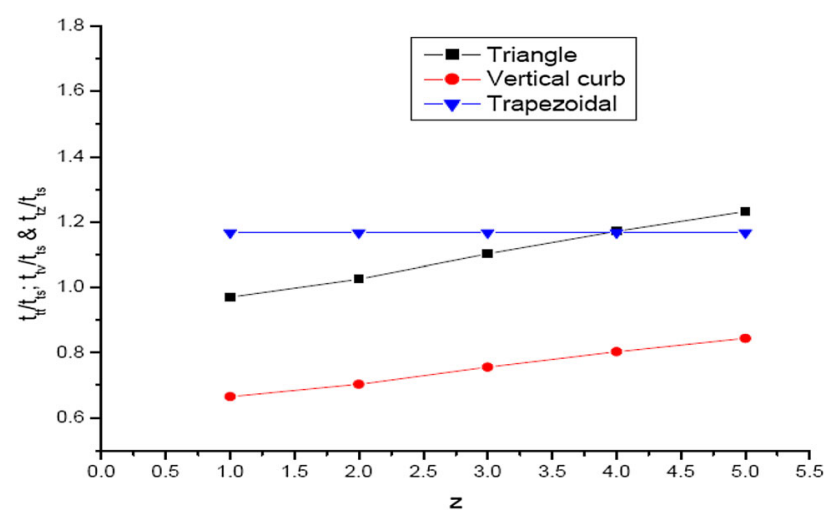

Fig. 2 Variation of $\mathrm{O}, \mathrm{T}$ and $\mathrm{V}$ types of channel with respect to travel time

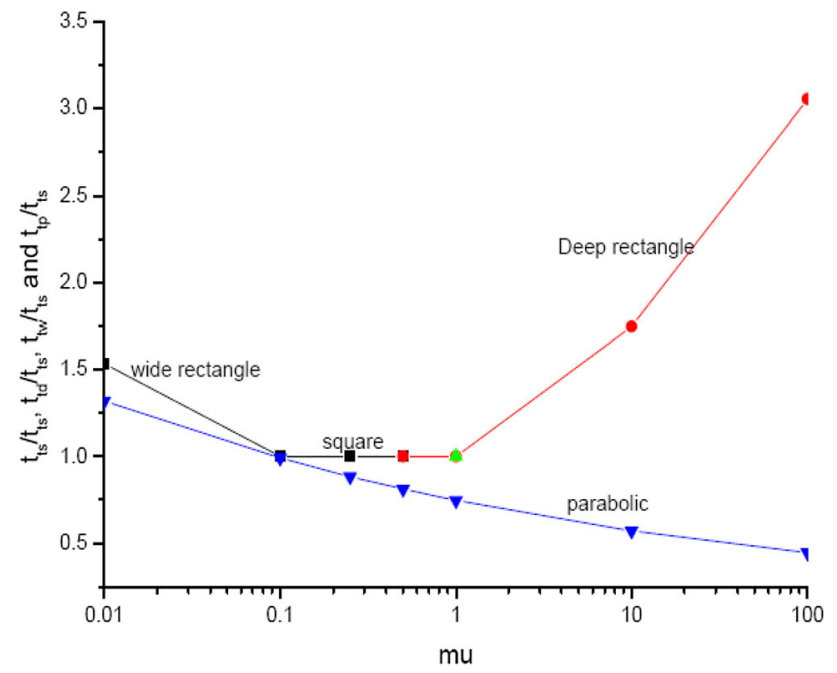

Fig. 3 Variation of W, D, S and P channels with respect to travel time

value and then starts increasing for the O-type channel. Figures 2 and 3 show the comparative behavior which is discussed in a later section.

\section{Comparative Assessments of Travel Time for T, E, $O$ and V Channels}

The travel time in the $\mathrm{T}$ and $\mathrm{O}$ types of channel is identical for a channel with " $z$ " and " $1 / z$ ". Figure 2 displays the travel time ratio curves " $t_{\mathrm{tt}} / t_{\mathrm{ts}}, t_{\mathrm{tv}} / t_{\mathrm{ts}}$ and $t_{\mathrm{ttz} 2} / t_{\mathrm{ts}}$ ", for $z=0.1-5$. A lesser value of " $z$ " characterizes a channel by sharp side slope (SSS), whereas the large value of " $z$ " characterizes a channel by the mild side slope (MSS). On the evaluation of Fig. 2, for T type of channel having more travel time, $t_{\mathrm{tt}} / t_{\mathrm{ts}}$ varies from 0.970 to 1.232 , for $\mathrm{V}$ type of channel, $t_{\mathrm{tv}} / \mathrm{t}_{\mathrm{ts}}$ varies from 1.034 to 1.456 , and for $\mathrm{O}$ channel $t_{\mathrm{ttz} 2} / \mathrm{t}_{\mathrm{ts}}$ ranges from 1.167 to 1.750 . Therefore, one can say that the travel time for V-and O-type channels is nearby. Further, figures also indicate that all the curves have a decreasing trend with increasing the value of " $z$ ", reach the lowest and then escalate with increasing value of " $z$ ".

Figure 2 additionally demonstrates that for channels with SSS (low value of $\mathrm{z}$ ), the travel time for the V channel is longer and bigger than those for the T channel, which is compared to more prominent stream resistance in the $\mathrm{V}$ channel. On the other hand, for channels with MSS (more value of $\mathrm{z}$ ), the figures demonstrate that the travel time for the $\mathrm{T}$ channel is longer and bigger than those for the $\mathrm{V}$ channel, which is compared to more prominent stream resistance in the $\mathrm{T}$ channel.

\section{Comparative Assessments of Travel Time for Rectangular and Parabolic Channels}

Figure 3 shows that ratio of the travel time of $\mathrm{D}, \mathrm{W}$ and $\mathrm{P}$ channel with respect to S channel $t_{\mathrm{tw}} / t_{\mathrm{ts}}, t_{\mathrm{td}} / t_{\mathrm{ts}}, t_{\mathrm{ts}} / t_{\mathrm{ts}}$ and $t_{\mathrm{tp}} /$ $t_{\mathrm{ts}}$, for the value of $\lambda=0$ and 1 and $\mu=0.01-1000$. A low value of " $\mu$ " describes a rectangular or parabolic channel with little flow depth, and large value of " $\mu$ " describes a rectangular or parabolic channel with huge flow depth. The estimations of the value of $\lambda$ for 0 and 1 express channels without and with upstream discharge. For the $\mathrm{W}$ channel, the ratio of travel time $t_{t w} / t_{t s}$ diminishes with expanding value of $\mu$ and $\lambda$, which relates to diminishing flow resistance with expanding flow depth and upstream discharge, when contrasted with that of the square channel. On the other hand, for the $\mathrm{D}$ channel, the ratio $t_{\mathrm{td}} / t_{\mathrm{ts}}$ increases with expanding $\mu$ and $\lambda$, which is related to increasing flow resistance with increasing flow depth and upstream discharge, when contrasted with that of the square channel. Further, as the flow resistance for the $\mathrm{W}$ channel is contributed from the base of the channel (i.e., like one side of the $\mathrm{D}$ channel), and for the $\mathrm{D}$ channel, it is from two sides of the channel, the estimation of $t_{\mathrm{td}} / t_{\mathrm{ts}}$ for $\mu=100$ is around twice that for $t_{t w} / t_{t s}$ for $\mu=0.01$. For the $\mathrm{P}$ channel, $t_{t p} / t_{t s}$ diminishes with expanding $\mu$ and $\lambda$, which is related to diminishing flow resistance with expanding flow depth and upstream discharge, when contrasted with that of the square channel. For channels with little flow depth, the flow conditions in the $\mathrm{W}$ channel and $\mathrm{P}$ channel are comparative. Without a doubt, the figures demonstrate that for little value of " $\mu$ ", the ratios $t_{t w} / t_{t s}$ and $t_{t p} / t_{t s}$ are near to each other.

Table 2 demonstrates that the alteration in the travel time proportions between $\lambda=1$ and 100 is little. The impact of the upstream discharge on the travel time ratio is low. The value corresponds to $\lambda=100$ demonstrating that the travel time among different channel profiles could be as much as sixfolds; accordingly, it proves that travel time has a significant role. Among the nine channel profiles [deep 
Table 2 Comparison of nine channel profiles on travel time

\begin{tabular}{|c|c|c|c|c|c|}
\hline \multicolumn{2}{|l|}{$\lambda=0$} & \multicolumn{2}{|l|}{$\lambda=1$} & \multicolumn{2}{|l|}{$\lambda=100$} \\
\hline Channel profile & $t_{\mathrm{t}} / t_{\mathrm{ts}}$ & Channel profile & $t_{\mathrm{t}} / t_{\mathrm{ts}}$ & Channel profile & $t_{\mathrm{t}} / t_{\mathrm{ts}}$ \\
\hline $\mathrm{D}(\mu=100)$ & 2.581 & $\mathrm{D}(\mu=100)$ & 3.184 & $\mathrm{D}(\mu=100)$ & 3.437 \\
\hline $\mathrm{E}(\psi=0.01, z=5)$ & 1.911 & $\mathrm{E}(\psi=0.01, z=5)$ & 1.911 & $\mathrm{E}(\psi=0.01, z=5)$ & 1.911 \\
\hline $\mathrm{E}(\psi=0.01, z=1)$ & 1.850 & $\mathrm{E}(\psi=0.01, z=1)$ & 1.850 & $\mathrm{E}(\psi=0.01, z=1)$ & 1.850 \\
\hline $\mathrm{O}(\psi=0.01, z=1)$ & 1.846 & $\mathrm{O}(\psi=0.01, z=1)$ & 1.846 & $\mathrm{O}(\psi=0.01, z=1)$ & 1.846 \\
\hline $\mathrm{E}(\psi=0.01, z=0.2)$ & 1.843 & $\mathrm{E}(\psi=0.01, z=0.2)$ & 1.843 & $\mathrm{E}(\psi=0.01, z=0.2)$ & 1.843 \\
\hline $\mathrm{W}(\mu=0.01)$ & 1.828 & $\mathrm{~W}(\mu=0.01)$ & 1.534 & $\mathrm{~W}(\mu=0.01)$ & 1.489 \\
\hline $\mathrm{P}(\mu=0.01)$ & 1.613 & $\mathrm{P}(\mu=0.01)$ & 1.516 & $\mathrm{P}(\mu=0.01)$ & 1.464 \\
\hline $\mathrm{V}(z=0.2)$ & 1.456 & $\mathrm{~V}(z=0.2)$ & 1.456 & $\mathrm{~V}(z=0.2)$ & 1.456 \\
\hline $\mathrm{O}(\psi=100, z=0.2)$ & 1.360 & $\mathrm{O}(\psi=100, z=0.2)$ & 1.360 & $\mathrm{O}(\psi=100, z=0.2)$ & 1.360 \\
\hline $\mathrm{E}(\psi=100, z=5)$ & 1.232 & $\mathrm{E}(\psi=100, z=5)$ & 1.232 & $\mathrm{E}(\psi=100, z=5)$ & 1.232 \\
\hline $\mathrm{T}(z=0.2$ and 5$)$ & 1.232 & $\mathrm{~T}(z=0.2$ and 5$)$ & 1.232 & $\mathrm{~T}(z=0.2$ and 5$)$ & 1.232 \\
\hline $\mathrm{E}(\psi=100, z=0.2)$ & 1.180 & $\mathrm{E}(\psi=100, z=0.2)$ & 1.180 & $\mathrm{E}(\psi=100, z=0.2)$ & 1.180 \\
\hline $\mathrm{O}(\psi=100, z=5)$ & 1.131 & $\mathrm{O}(\psi=100, z=5)$ & 1.131 & $\mathrm{O}(\psi=100, z=5)$ & 1.131 \\
\hline $\mathrm{V}(z=5)$ & 1.131 & $\mathrm{~V}(z=5)$ & 1.131 & $\mathrm{~V}(z=5)$ & 1.131 \\
\hline $\mathrm{V}(z=1)$ & 1.064 & $\mathrm{~V}(z=1)$ & 1.064 & $\mathrm{~V}(z=1)$ & 1.064 \\
\hline $\mathrm{O}(\psi=100, z=1)$ & 1.044 & $\mathrm{O}(\psi=100, z=1)$ & 1.044 & $\mathrm{O}(\psi=100, z=1)$ & 1.044 \\
\hline & - & & - & $\mathrm{C}$ & 1.009 \\
\hline $\mathrm{S}(\mu=1)$ & 1.000 & $\mathrm{~S}(\mu=1)$ & 1.000 & $\mathrm{~S}(\mu=1)$ & 1.000 \\
\hline & - & $\mathrm{C}$ & 0.993 & & \\
\hline $\mathrm{T}(z=1)$ & 0.970 & $\mathrm{~T}(z=1)$ & 0.970 & $\mathrm{~T}(z=1)$ & 0.970 \\
\hline $\mathrm{E}(\psi=100, z=1)$ & 0.964 & $\mathrm{E}(\psi=100, z=1)$ & 0.964 & $\mathrm{E}(\psi=100, z=1)$ & 0.964 \\
\hline $\mathrm{C}$ & 0.946 & & - & & - \\
\hline $\mathrm{P}(\mu=1)$ & 0.912 & $\mathrm{P}(\mu=1)$ & 0.857 & $\mathrm{P}(\mu=1)$ & 0.842 \\
\hline $\mathrm{O}(\psi=0.01, z=5)$ & 0.590 & $\mathrm{O}(\psi=0.01, z=5)$ & 0.590 & $\mathrm{O}(\psi=0.01, z=5)$ & 0.590 \\
\hline $\mathrm{P}(\mu=100)$ & 0.543 & $\mathrm{P}(\mu=100)$ & 0.511 & $\mathrm{P}(\mu=100)$ & 0.502 \\
\hline
\end{tabular}

rectangular (D); wide rectangular (W); square (S); triangular (T); parabolic (P); vertical curb (V); circular (C); trapezoidal with equal side slopes $(\mathrm{E})$; and trapezoidal with one side vertical $(\mathrm{O})]$, the one that delivers the longest travel time is the $\mathrm{D}(\mu=100)$. Henceforth, the utilization of this channel produces littler watershed runoff. The channel that creates the most limited time of travel is the $\mathrm{P}$ channel with extensive stream depth $(\mu=100)$. Henceforth, the utilization of this channel creates a bigger watershed runoff.

In case of heavy rainfall, inappropriate design of channel may lead to cause of flooding in developing nations where channel is either not properly designed or if designed not sustain the flow of water, which hinder the free flow of excess storms when they occur. Therefore, practically this study revealed that the best channel in extreme rainfall too hole maximum flood by increasing the travel time of the flow increases the lag time and thus save the likely causes of major disaster as well as flow variability among the different channels.

\section{Conclusions}

On coupling, the Manning's equation with kinematic wave parameters ( $\alpha$ and $\beta$ ) has been used to find the best suited channels for smaller watershed runoff which can add to flood management tools. The estimation of wave parameters $(\alpha$ and $\beta$ ) for different channels is efficient in decision support tools in mitigating climate induced hazards such as flood and drought. A new approach for the design of channel network on the basis of the time of travel has been envisaged in the present work using the integration of kinematic wave theory with the Manning's equations. On the basis of its verification and by means of the derived formulas, the effect of channel profile on the time of travel for nine channel profiles has been compared on a unified basis and the following conclusions were drawn:

1. It also shows that channel profile can cause a sixfold increase in time of travel.

2. Of the nine channel profiles, the one that produces the longest time of travel is the deep rectangular channel. 
Hence, the use of this channel produces smaller watershed runoff.

3. The channel that produces the shortest time of travel is the parabolic channel with large flow depth. Hence, the use of this channel produces relatively larger watershed runoff.

4. The order of selecting a channel that produces the longest time of travel to least time of travel is as deep rectangular, a trapezoidal channel with equal side slopes, wide rectangular, square, triangular, circular and parabolic.

\section{Appendix I}

See Table 3 .

Table 3 Schematic sketch of different channels

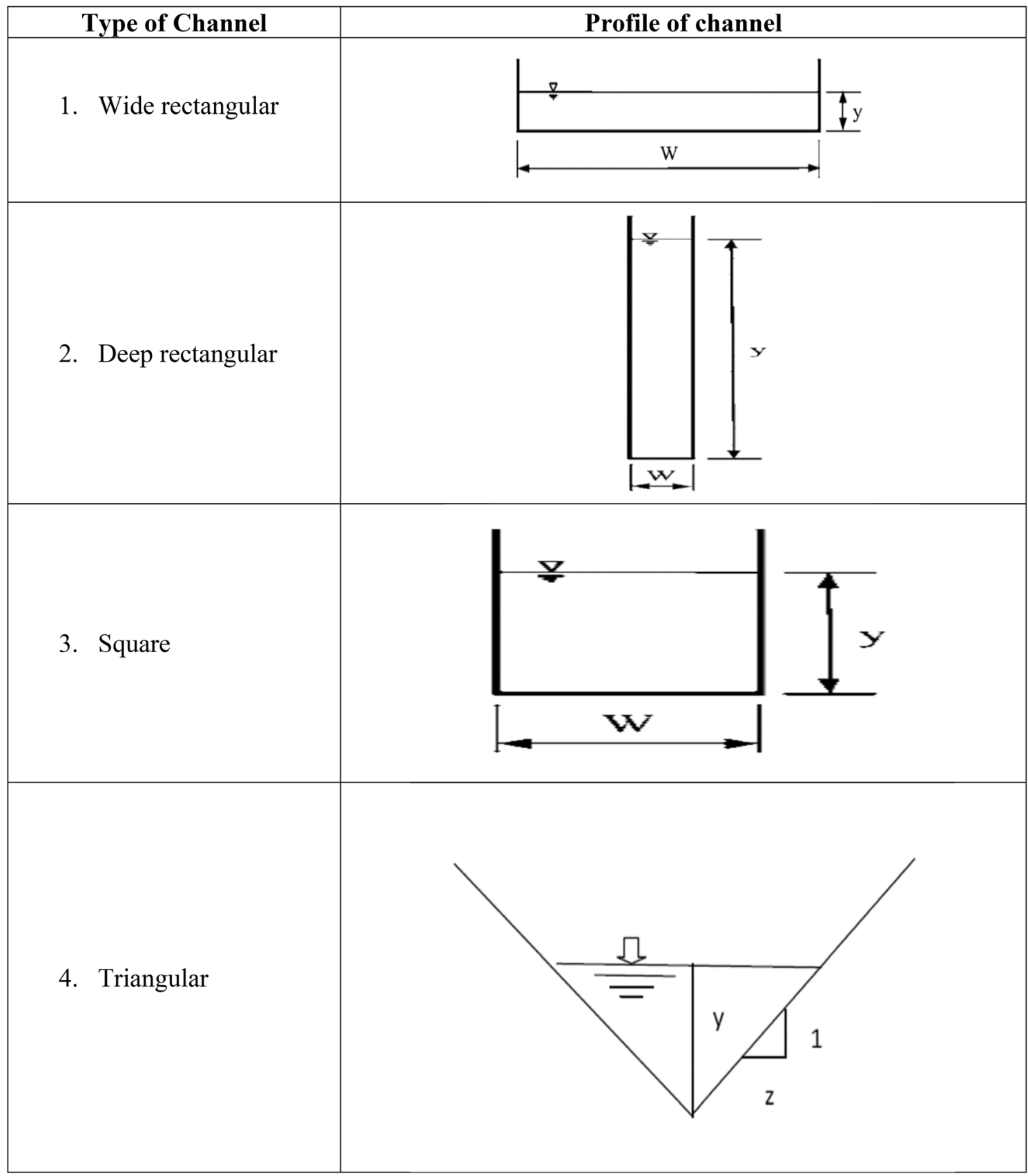


Table 3 continued

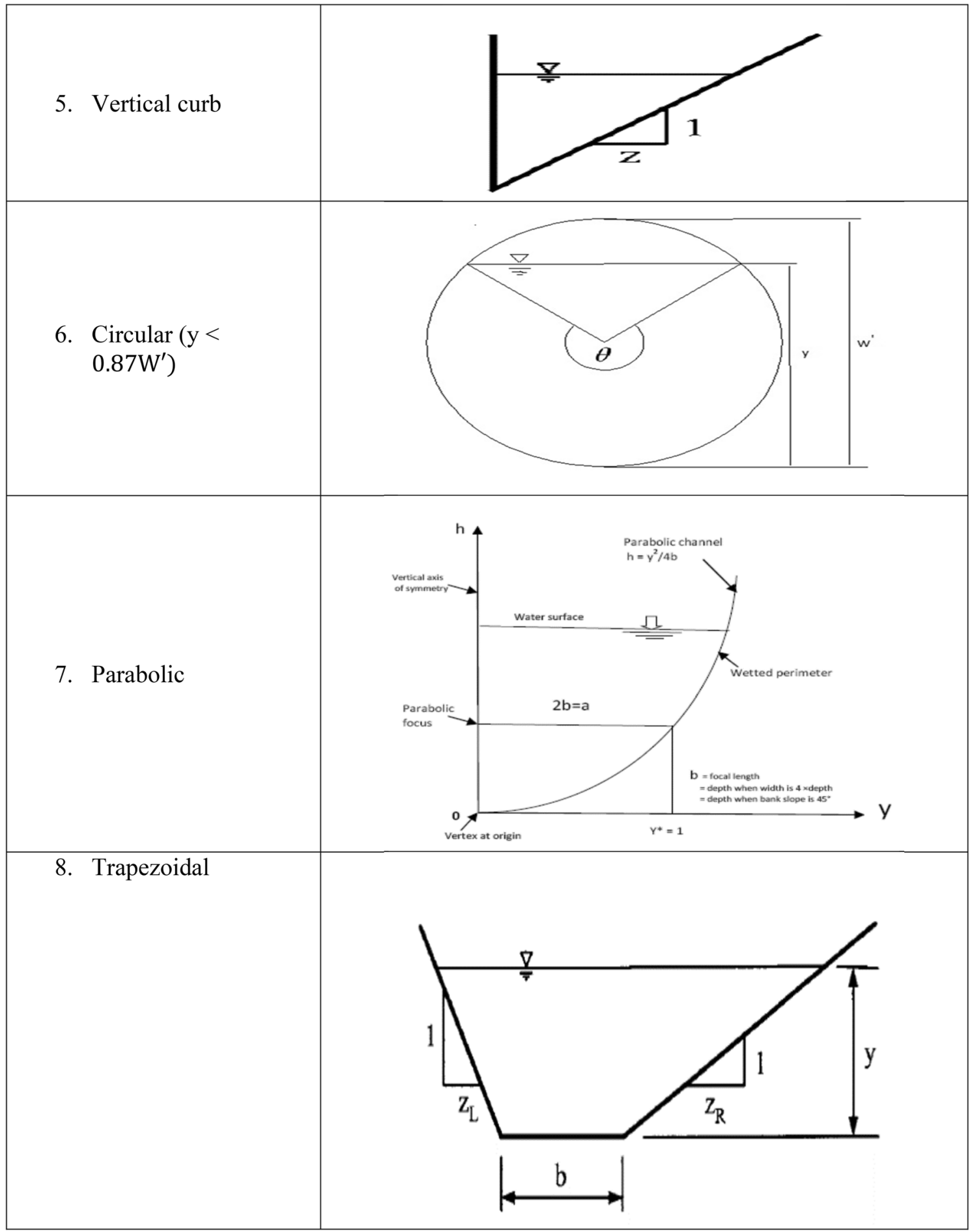




\section{References}

1. A.P. Mironenko, L.S. Willardson, S.A. Jenab, Parabolic canal design and analysis. J. Irrig. Drain. Eng. 110(2), 241-246 (1984)

2. T.S.W. Wong, Time of concentration and peak discharge formulas for planes in series. J. Irrig. Drain. Eng. 122(4), 256-258 (1996)

3. F.M. Henderson, R.A. Wooding, Overland flow and groundwater flow from a steady rainfall of finite duration. J. Geophys. Res. 69(8), 1531-1540 (1964)

4. T.S.W. Wong, Use of resistance coefficient derived from single planes to estimate time of concentration of two-plane systems. J. Hydraul. Res. 40(1), 99-104 (2002)

5. V.T. Chow, Open channel hydraulics (McGraw-Hill, Henderson, 1959)

6. D.A. Woolhiser, J.A. Liggett, Unsteady one-dimensional flow over a plane-the rising hydrograph. Water Resour. Res. 3(3), 753-771 (1967)

7. U.S. Department of Agriculture, Urban Hydrology for small watershed. Soil conservation service-Engineering Div. Tran. vol. 55 (1986)

8. C.N. Chen, T.S.W. Wong, Critical rainfall duration for maximum discharge from overland plane. J. Hydraul. Eng. 119(9), 1040-1045 (1993)
9. P.K. Swamee, G.C. Mishra, B.R. Chahar, Design of minimum seepage loss canal sections. ASCE J. Irrig. Drain. Eng. 126, 28-32 (2000)

10. T.S. Wong, Assessment of time of concentration formulas for overland flow. J. Irrig. Drain. Eng. 131(4), 383-387 (2005)

11. B.R. Chahar, Optimal design of parabolic canal section. J. Irrig. Drain. Eng. 131(6), 546-554 (2005)

12. S.M. Easa, Improved channel cross section with segment parabolic sides and horizontal bottom. J. Irrig. Drain. Eng. 135(3), 357-365 (2009)

13. S. Munier, G. Belaud, X. Litrico, A closed-form analytic expression for the response time of an irrigation canal. J. Irrig. Drain. Eng. 136(10), 677-684 (2010)

14. V.T. Chow, Open channel hydraulics (McGraw-Hill, New York, 1973)

15. T.S.W. Wong, Formulas for time of travel in channel with upstream inflow. J. Hydrol. Eng. 6(5), 416-422 (2001)

Publisher's Note Springer Nature remains neutral with regard to jurisdictional claims in published maps and institutional affiliations. 